\title{
COSMOPOLITIZAÇÃO DAS PROBLEMÁTICAS DA AVALIAÇÃO ESCOLAR NO SISTEMA DE ENSINO PORTUGUÊS E BRASILEIRO
}

\author{
André Freitas Santos ${ }^{1}$
}

\section{Resumo}

Este artigo tem em consideração o estado e as políticas praticadas em Portugal e no Brasil sobre a perspetiva da avaliação escolar e da avaliação externa. Neste sentido são exploradas, no presente, lógicas de análise dos critérios de avaliação, teorias e conceitos da avaliação e as suas vulnerabilidades e oportunidades a partir da recolha de dados. Contemplando a avaliação (escolar) participativa em sala de aula; a avaliação (externa) como análise e compreensão da certificação de estudantes; e a avaliação como diálogo relacional participativo.

Palavras-chave: avaliação escolar; avaliação externa; rankings escolares; classificação quantitativa; agentes educativos;

\section{COSMOPOLITIZATION EVALUATION OF PROBLEMS IN SCHOOL EDUCATION SYSTEM AND BRAZILIAN PORTUGUESE}

\section{Abstract}

This article takes into account the state and the politics adopted in Portugal and Brasil on the perspective of school evaluation and external evaluation. In this sense are explored in the present, logical analysis of the evaluation criterial, theories and concepts of assessment and their vulnerabilities and opportunities from the data

\footnotetext{
${ }^{1}$ Faculdade de Psicologia e de Ciências da Educação da Universidade do Porto. Porto Portugal. Departamento de Ciências da Educação - Planificação, Supervisão e Avaliação em Educação. Contato autor: andrefsantos27@gmail.com www.afreitassantos.pt.vu
}

Criar Educação, Criciúma, v. 7, no1, jan/jul 2018.- PPGE - UNESC 
collection. Contemplating the evaluation (school) participative in class; evaluation (external) as analysis and understanding of student certification; and evaluation as participatory relational dialogue.

Keywords: school evaluation; external evaluation; school rankings; quantitative classification; educators;

A avaliação escolar pressupõe uma autonomia curricular, construindo um espaço de identidade (Pacheco, 2002). Inicial, contínua e final são os momentos abordados e avaliados sobre um sistema de funcionalidade diagnóstica, formativa e sumativa, elaboradas numa perspetiva construtivista da aprendizagem (Fernandes, 2006). Verificar os conhecimentos do aluno adquiridos no ano anterior é visto como uma avaliação que reunirá critérios para determinar os processos de ensino-aprendizagem ao longo das aulas e capacitará os professores de criarem avaliações objectivas.

A avaliação não é, portanto, independente do processo de ensino aprendizagem, não pode ser considerada como um elemento final, devendo ser vista como um exercício de motivação e análise de capacidades e atitudes que é parte integrante do processo de ensino-aprendizagem. É entendida também como um campo subjetivo, obedecendo a critérios, capaz de ajustar políticas e promover a autonomia dos alunos.

Entre a clarificação dos objetivos de aprendizagem e a negociação dos critérios de avaliação, surge a interpretação e o confronto dos alunos. Estes tornam-se capazes de agirem sobre uma atitude autónoma, perspectivando uma escola existente para a promoção do sucesso educativo. Numa estreita relação, que deve de existir, da avaliação formativa com a avaliação sumativa, é da responsabilidade dos conselhos pedagógicos, das direcções de escolas, dos professores e de uns tantos outros departamentos científicos que trabalham directa ou indirectamente com os alunos terem em consideração os critérios objetivos de avaliação, devendo estes, serem compreensivos.

Criar Educação, Criciúma, v. 7, no1, jan/jul 2018.- PPGE - UNESC 
No processo de avaliação formativa e sumativa a presença dos diferentes agentes educativos é preciosa. Durante a construção de um educando, o professor vai ser um elemento presente durante um curto período da sua vida, contudo é o Encarregado de Educação, a família e a comunidade que estarão em constante aprendizagem com o aluno e serão um grande factor de influência e orientação, devendo então, estes últimos, ocupar um papel central no seu desenvolvimento, acompanhando as suas ideias, os seus conceitos, as suas interacções sociais e as suas políticas.

A avaliação formativa é uma variável, deve ser uma variável! O estado do país não é um fenómeno estagnado e por isso o acompanhamento dos alunos em sala de aula, também não o deve ser, tornando desta forma os professores responsabilizados pela pro atividade e preocupação com 0 exterior, para no seio do trabalho com os alunos não existirem práticas desiguais da realidade.

A desordem e a incongruência de atitudes em sala de aula, face ao professor, devem-se à fraca avaliação que têm desenvolvido, pois não acompanham os progressos já alcançados pelos alunos e pelo que os rodeia, contudo esta crítica deve ser assumida por todos nós, pelos Encarregados de Educação e pelas famílias, para desta forma o trabalho desenvolvido e as práticas de avaliação aplicadas serem construtoras de personalidade e promotoras do sucesso dos alunos.

As escolas devem ter como funções a contínua consciencialização problemática do seu meio e ser motor do discurso hermenêutico, proporcionando e impulsionando a capacidade interpretativa dos alunos. Perceba-se que actualmente existem em Portugal cento e vinte e uma instituições superiores de ensino púbicas e privadas. Existiu uma massificação do ensino e por conseguinte a necessidade de avaliação ser alterada e reestruturada para os atuais desafios. 
No governo da Manuela Ferreira Leite, por exemplo, a entrada de alunos no ensino superior alcançou números astronómicos, aproximando-se dos oitenta mil candidatos, em 1996/97 (OCES, 2006). Estas alterações, com repercussões sociais, deve-se à força que a avaliação detém e que a mesma pode gerar.

Não é possível avaliarmos competências/ objetivos/ metas curriculares se estas não forem valorizadas pela sociedade, pois é para a comunidade que os professores trabalham, comprometendo-se a um contra-senso. Segundo Pacheco (2002) "Trata-se de um jogo que implica a apropriação de critérios, na medida em que estes resultam da participação de todos" (p.4).

A avaliação sumativa deve, portanto, ser um reflexo da avaliação formativa, onde a subjectividade do professor deve ser discutida com os diferentes juízos de valor dos educandos, Encarregados de Educação e comunidade.

A teoria behaviourista e a sua relação com a avaliação formativa é mal definida quanto à sua intenção e portanto a designação de avaliação formativa alternativa (AFA) parece mais adequada (Fernandes, 2006). Sendo a avaliação formativa orientada para o acompanhamento dos alunos, todas as avaliações tornam-se então alternativas no seu contexto em relação com as avaliações externas que recorrem aos processos de classificação, selecção e certificação.

Citando Fernandes (2008) é possível perceber que os exames nacionais (no âmbito das avaliações externas) têm como "principais funções a certificação de saberes, o controlo do desenvolvimento e cumprimento do currículo, a selecção dos alunos (...) e a avaliação do sistema educativo" (p.279). É sobre este último que os resultados dos exames tornam-se ilusórios e bacocos.

Um resultado nacional de uma avaliação externa que defina que 0 ensino em Portugal ou no Brasil é fraco, através dos resultados de alunos do Criar Educação, Criciúma, v. 7, no1, jan/jul 2018.- PPGE - UNESC 
país, não diz nada. Não acrescenta qualquer conteúdo para uma problematização, não é específico, concreto e realista do trabalho construído pelos professores com os alunos, não adicionando desta forma melhorias para os mesmos.

Uma competição entre a importância avaliativa dos saberes dos alunos é posta em causa, pois as avaliações externas comandam o que os alunos devem saber, como o devem saber e como os professores os devem ensinar (Fernandes, 2008). A avaliação deve ser experimentada e vivenciada pelos alunos como um diálogo, um espaço de partilha e não como um decisor final, de caracter certificativo, impessoal e imparcial.

A competição, provocada por meios externos, transportou para as escolas uma autonomia certificativa, desenvolvendo "rankings" próprios. A instituição de ensino secundário é tema de conversa e de orgulho ou crítica, quando esta surge no topo ou no final do ranking nacional. Para manter ou subir a posição no aclamado painel numérico as escolas recebem e transportam os alunos para um fim objectivo, demonstrando e questionando que interesse estamos a incutir nos jovens.

Como é que ao prepará-los para o ranking nacional estamos a construir um canal de relação? Qual é o propósito da educação? Qual é o propósito da avaliação?

No ensino privado é histórico os dados apresentados e salientados pelas instituições de alunos cuidadosamente seleccionados, provenientes de famílias pormenorizadamente trabalhadas, que entraram nas melhores Faculdades. Durante este tempo de aprendizagem, eles não aprenderam. Eles não brincaram. Eles não construíram. Eles não sentiram a terra. Eles não sujaram as calças. Eles não aprenderam nada. Foram pequenos trabalhadores programados para um fim maior do que eles. 
A educação e as provas que esta tem de prestar seguem os parâmetros definidos pela economia, pelas instituições públicas que são responsáveis pelas políticas públicas e o conteúdo da avaliação é vista como um parâmetro de competências e habilidades, contudo o sistema educativo é culpabilizado pela qualidade, sucesso e fracasso dos professores e alunos, quando é este quem as define (Peroni, 2009).

No Brasil, assim como em Portugal, as provas de avaliação externa são necessárias para objectivamente expor as classificações e dar a conhecer os efeitos do período de escolarização referente. Como por exemplo, a capacidade de compreensão, de análise e de raciocínio dedutivo, que segundo os resultados das avaliações do 12ํ decorrentes entre os anos de 1999 e 2001 em Portugal apresentavam características fracas, contrariando resultado satisfatórios quando os alunos respondiam às questões de reprodução mecanizada (GAVE, 2002).

No Brasil, entre as muitas provas de avaliação externa a que é sujeito, um dos mais problemáticos e contraditórios, devido às grandes diferenças culturais e sociais existentes no país, são as avaliações ENEM, pois as competências ou incompetências dos alunos, independentemente do seu contexto define o seu sucesso ou fracasso, ignorando a responsabilidade do estado pela sua qualidade da oferta educativa, de acordo com Peroni (2009), citando Sousa (2003).

Os alunos são então uma ferramenta essencial para dar continuidade às exigências do capital e das grandes indústrias. As suas habilidades devem ser trabalhadas para um propósito mais formativo, pois é onde reside a essência da construção da identidade de um cidadão e de um profissional, apropriandose das suas características, do seu contexto, adaptando as metodologias de ensino-aprendizagem e desenvolvendo relações colaborativas.

Contudo ainda é a certificação da avaliação externa que possibilita a este cidadão em construção um futuro profissional e social. A avaliação externa não deve ser ignorada! Deve é ser moderada e após reunidas as Criar Educação, Criciúma, v. 7, no1, jan/jul 2018.- PPGE - UNESC 
verdadeiras condições de avaliação, ser aplicada. As condições a existirem passam pelo verdadeiro contacto com as escolas, com as comunidades, compreendendo os conflitos, obstáculos e as suas potencialidades.

É possível avaliar externamente um aluno, com critérios objetivos, desde que esteja em concordância com os conceitos a que ele foi exposto e conheceu. Não avaliemos externamente uma criança sobre a sua capacidade de interpretação, sendo que nunca the foram reunidas as condições e possibilidades de ler um livro ou de fazer um desenho. Os jovens devem ser consultados a propósito das avaliações e das atividades a desenvolver, pois são eles quem vão apresentar os resultados desses processos. O que deve estar em consideração é o papel do professor e a sua relação e proximidade com o aluno.

O professor sempre manterá a sua postura central e hierárquica. É necessário que o faça, pois, no ensino formal, existe de facto uma transmissão de informação que depois relacionada com o aluno é vista como conhecimento pelo mesmo. A decisão unanime e uniforme entre professor e estudantes é a chave para uma natureza pedagógica rica, capaz de fomentar reflexão, com a criação de debates e ciclos de cinema nas associações de estudantes.

Avaliar o que os alunos sabem e são capazes de fazer dentro da sala de aula deve ser uma política educativa a valorizar e a investir (Fernandes, 2008). Vejamos o exemplo do Programa Internacional de Avaliação de Estudantes (PISA) onde alunos com quinze anos de idade são sorteados para uma prova onde existem como principais objetivos de avaliação, averiguar as competências dos jovens, percebendo se estão aptos a exercer um papel de cidadão na sociedade contemporânea (OCDE, 2012), não interessando se os alunos a quem esta prova é entregue, frequentam o 9ำ ano de escolaridade do ensino básico ou se ainda não transitaram do 6ํano de escolaridade.

Quando deixaremos de usar os alunos como ferramentas para conquistar o ranking europeu, selecionando-os, certificando-os e Criar Educação, Criciúma, v. 7, no1, jan/jul 2018.- PPGE - UNESC 
desenvolvendo novas parcerias monetárias, passando sim, a trabalhar em conjunto com eles para formarmos pessoas interessadas numa cidadania ativa e capazes de se expressarem e desafiarem os seus próprios saberes?

Não se pode dissociar a avaliação externa da avaliação escolar. Estas devem ser complementos e fontes de informação capazes de gerar a classificação que é necessária de existir para um aluno. Não podemos reduzir a ideia de um número, pois é com ele que vivemos o nosso quotidiano em sociedade, está em nosso redor e é usado para nos identificarmos. Para deixarmos de classificar os estudantes era preciso existir uma ruptura, que em luta pode ser uma batalha ganha ou uma falha colossal que teria impactos sociais graves, para a qual, pessoalmente ainda não estou preparado.

O que tem de existir é uma grande transformação de comportamentos e atitudes referentes a esta classificação. Para chegarmos à classificação a avaliação não pode especificar as ciências matemáticas e as línguas, ignorando as expressões culturais e os comportamentos sociais dos alunos. A classificação pode ser um mecanismo trabalhado e programado para uma metodologia sujeita à reflexão da avaliação, construída por todos os agentes educativos, ao longo da aprendizagem do aluno.

Os professores têm um papel extremamente importante para completar as falhas das avaliações externas, que definem quem terá oportunidade de ingresso na Faculdade de Medicina, com as avaliações formativas. Mas verdade seja que esse possível ingresso só será permitido se durante as avaliações formativas e sumativas em que 0 aluno participou, reuniu informações suficientes para alcançar a avaliação externa e demonstrar conhecimento aplicado.

As avaliações formativas devem ser subjectivas, respeitando os critérios de avaliação. O professor necessita de ser subjectivo e capaz de avaliar os complexos processos de pensamento dos alunos, revelando na sua classificação um verdadeiro somatório de experiências e saberes conquistados. 
Para Santos (2008) a avaliação deve ser vista como um processo de diálogo. Segundo Pacheco (2002), "Avaliar é comunicar" (p.5) e Fernandes (2006) afirma que "A avaliação é um processo desenvolvido por e com seres humanos para seres humanos" (p.36).

Para mim, avaliar é relacionar. A avaliação é a relação que existe entre o professor, a comunidade, nomeadamente o Encarregado de Educação e 0 aluno. Uma constante aprendizagem dos intervenientes, é disto de que se trata a avaliação. Uma relação que deve preservar e salientar a importância de todos para todos, alcançando uma escola orientada para o sucesso e um mundo dirigido para as pessoas.

\section{Referências}

FERNANDES, D. (2006). Para uma teoria da avaliação formativa. In CIEd Universidade do Minho (Eds.), Revista Portuguesa de Educação (pp.21-50).

FERNANDES, D. (2008). Algumas reflexões acerca dos saberes dos alunos em Portugal. Educação. Sociedade. (vol. 29. pp. 275 - 296). Campinas.

FERNANDES, D. (2008) apud PORTUGAL. Ministério da Educação (GAVE, 2001). Provas de aferição do ensino básico: 4 e 6ำ anos. Lisboa: Ministério da Educação.

FERNANDES, D. (2008) apud PORTUGAL. Ministério da Educação (GAVE, 2002). Gabinete de Avaliação Educacional. Contributo para uma melhor compreensão do desempenho dos alunos nos exames do 12ano. Lisboa: Gave.

PACHECO, J. (2002). Critérios de avaliação na escola. In Avaliação das aprendizagens: das concepções às práticas (pp.53-64). Lisboa: Departamento da Educação Básica

PACHECO, J. (2002) apud PACHECO, J (1996). A avaliação dos alunos na perspetiva da Reforma ( $2^{\circ}$ ed.). Porto: Porto Editora.

PERONI, V. (2009). Avaliação institucional em tempos de redefinição do papel do Estado. In. RBPAE (vol. 25, № 2, pp. 285 - 300). 
SANTOS, L. (2008). Dilemas e desafios da avaliação reguladora. In L. Menezes, L. Santos, H. Gomes \& C. Rodrigues (Eds.), Avaliação em Matemática: Problemas e desafios (pp. 11-35). Viseu: Secção de Educação Matemática da Sociedade Portuguesa de Ciências de Educação.

SANTOS, L. (2008) apud NUNZIATI, G. (1990) Pour construire un dispositif d'évaluation formatrice. Cahiers Pédagogiques (pp. $47-64$ ).

SANTIAGO, P., et al. (2012), OECD Reviews of Evaluation and Assessment in Education: Czech Republic 2012. OECD Publishing.

Recebido em outubro 2017

Aprovado em março 2018 